John O. L. DeLancey

\title{
The pathophysiology of stress urinary incontinence in women and its implications for surgical treatment
}

\begin{abstract}
Stress urinary incontinence is a symptom that arises from damage to the muscles, nerves, and connective tissue of the pelvic floor. Urethral support, vesical neck function, and function of the urethral muscles are important determinants of continence. The urethra is supported by the action of the levator ani muscles through their connection to the endopelvic fascia of the anterior vaginal wall. Damage to the connection between this fascia and muscle, loss of nerve supply to the muscle, or direct muscle damage can influence continence. In addition, loss of normal vesical neck closure can result in incontinence despite normal urethral support. Although the traditional attitude has been to ignore the urethra as a factor contributing to continence, it does play a role in determining stress continence since in $50 \%$ of continent women, urine enters the urethra during increases in abdominal pressure, where it is stopped before it can escape from the external meatus. Perhaps one of the most interesting yet least acknowledged aspects of continence control concerns the coordination of this system. The muscles of the urethra and levator ani contract during a cough to assist continence, and little is known about the control of this phenomenon. That operations cure stress incontinence without altering nerve or muscle function should not be misinterpreted as indicating that these factors are unimportant.
\end{abstract}

John O. L. DeLancey

Department of Obstetrics and Gynecology,

University of Michigan Medical School,

Ann Arbor, Michigan, USA

J. O. L. DeLancey (四)

D2234 Medical Professional Building,

1500 East Medical Center Drive,

Ann Arbor, MI 48109-0718, USA

Tel.: + 1-313-764-1195; Fax: + 1-313-764-7261

E-mail: DeLancey@umich.edu
This article considers our biological understanding of the urinary continence mechanism and explores what this knowledge tells us about our current surgical approach to stress urinary incontinence.

\section{Historical background}

Progress has been made during this century in the surgical treatment of stress urinary incontinence. Kelly and Dumm [15] noticed that the vesical neck failed to close properly in many women with severe stress incontinence and used silk sutures to narrow the vesical neck in attempts to cure this problem. A few years later, Bonney [1] called attention to urethral support loss in stressincontinent women and plicated the fascia underneath the vesical neck to compensate for this loss of urethral support. In the late 1940s, Marshall et al. [17] reported an empirical observation that if the periurethral tissues were sutured to the pubic bone, stress incontinence could be alleviated. They had no observation concerning the cause of stress incontinence and warned that the success of their surgery should not be used to confirm any particular theory about the cause of stress urinary incontinence. Despite this admonition, common practice has been to use the success of stress incontinence surgery to make inferences about continence biology.

In the late 1970s the nature of urethral support loss was clarified by Richardson et al. [25], who identified the junction of the paravaginal endopelvic fascia with the arcus tendineus at the pelvic wall as the anatomic location where the urethral supports failed. Reattachment of the detached paravaginal tissues to the arcus tendineus alleviated stress incontinence in those women whose stress incontinence was caused by paravaginal defect. At about the same time, McGuire et al. [19] called attention to the importance of determining whether a woman's stress incontinence was caused by defective vesical neck 
function or abnormal support. They observed that a group of women existed whose stress incontinence was caused not by loss of urethral support but because of inadequate vesical neck closure and that these individuals constituted an important class of women who failed typical support operations for stress incontinence. These two observations suggested that treatment of stress-incontinent women should be based on the type of damage present rather than being the same for all women.

These observations have contributed significantly to our clinical management of stress urinary incontinence. As yet, however, the nature of incontinence defects have not yet been tested using the scientific method. During the same period in which these clinical observations have been made, data have been accumulating concerning changes in the pelvic muscle, nerve, and connective tissue. This article evaluates scientific observations of the stress-continence control system, considers the types of damage that manifest in women with stress incontinence, and evaluates how our treatment of stress incontinence might benefit from emerging information about the neuromuscular and fascial abnormalities that exist in incontinent women.

This remains a relevant exercise despite reports in the literature suggesting a high degree of success with surgery. Not only is there some question about whether these high success rates might be completely accurate but, in addition, these operations sometimes create new problems that leave some women cured of their stress incontinence but burdened with a new problem such as difficult voiding, detrusor instability, or enterocele.

\section{Stress-continence control system}

Surgery for stress urinary incontinence is effective in eliminating incontinence during increases in abdominal pressure. It does not, however, restore normal physiology. The continence mechanism comprises an elegantly organized series of nerves, muscles, and connective tissue that dynamically influence bladder control. This arrangement allows prompt and complete bladder emptying while also maintaining continence during tremendous increases in abdominal pressure.

The very dynamic nature of this continence control system is often overlooked in surgical discussions but is critical to our complete understanding of how continence is controlled. The dynamic nature of the continence system is likely discounted because operations are incapable of influencing the coordination and strength of the neuromuscular apparatus controlling continence. Therefore, a simpler view of continence is more attractive to both surgeon and patient. This observation should not be seen as a criticism of surgery for stress incontinence because operative therapy has proved to be remarkably effective despite its empirical nature. Progress, however, may result from a better understanding of the specific mechanism of continence.

\section{Nature of urethral support}

A lateral view of the pelvic organs displayed in Fig. 1 reveals the relevant anatomy of the continence control system [8]. It should be noticed that some structures have been cut away to reveal elements contributing to continence. The important components to be noticed first are the levator ani muscles, which run from the pubic bone to the anal sphincter and behind the rectum in a position where they can support the pelvic organs. These muscles lie lateral to the arcus tendineus fasciae pelvis, a band of endopelvic fascia that stretches between the public bone and the ischial spine. It should also be noticed how the endopelvic fascia unties the anterior vaginal wall (shown through a window cut in the lateral vaginal wall) to the arcus tendineus.

The layer formed by the anterior vaginal wall and its connection to the arcus tendineus fasciae pelvis by the endopelvic fascia forms a hammock-like layer in which the bladder and vesical neck rest [8]. Although this fascial support is usually thought to be a passive rather than an active mechanism, the connection between the fascia and the levator ani muscle is an important element of this system [7, 10]. This connection permits active contraction of the pelvic muscles to elevate the vesical neck and their relaxation to allow it to descend [21]. In addition, the normal constant activity of the levator ani muscles [23] supports the vesical neck during normal activities. It is my opinion that the role of the neuromuscular control of the urethral and levator ani muscles as well as their attachments to the urethral supportive tissues will likely prove to be one of the major determinants of urinary continence.

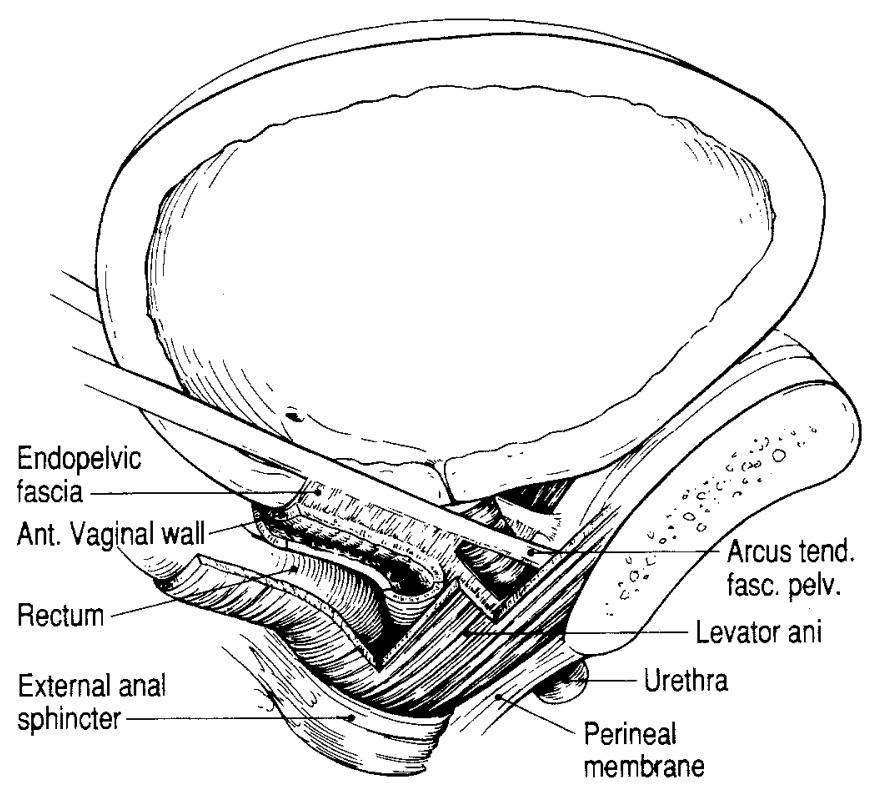

Fig. 1 Lateral view of the continence mechanism, showing the attachments of the endopelvic fascia to the arcus tendineus fasciae pelvis (Arcus tend. fasc. pelv.) and to the levator ani muscles [8] 


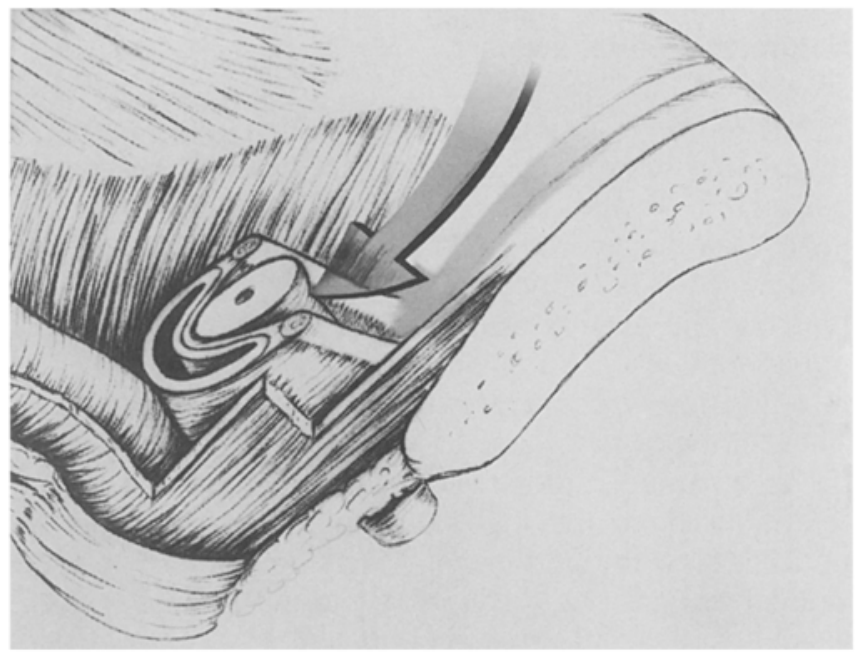

Fig. 2 View of the urethra and vagina, cut in cross section just below the vesical neck demonstrating how abdominal pressure (arrow) can compress the urethra against the underlying fascia [8]

A relevant question as yet unanswered is the following: how does this apparatus keep the urethra closed tightly enough that increases in vesical pressure during a forceful cough do not force urine out through the urethra (i.e., to maintain the positive pressure gradient where the urethral closure pressure is greater than the bladder pressure). Some preliminary insight into this question can be gained by examination of anatomic specimens using simulated increases in abdominal pressure. This view reveals that the urethra lies in a position where it can be compressed against the supporting hammock by rises in abdominal pressure (Fig. 2) [8]. In consideration of this layer it should be recognized that in normal women the anterior vaginal wall is in contact with the posterior vaginal wall, and further work will be needed to establish the relative contributions of these walls to urethral support.

In this conceptual model it is the stability of these supporting layers rather than the height of the urethra that determines stress continence. In an individual with a firm supportive layer the urethra would be compressed between abdominal pressure and pelvic fascia in much the same way that one can stop the flow of water through a garden hose by stepping on it and compressing it against an underlying sidewalk. If, however, the layer under the urethra becomes unstable and does not provide a firm backstop against which abdominal pressure can compress the urethra, the opposing force that causes closure is lost and the occlusive action is diminished. The latter situation is similar to that in which one tries to stop the flow of water through a garden hose by stepping on it while it lies on soft soil.

This analogy could help us explain why some patients who have a large cysto-urethrocele and in whom the urethra is far below its normal position might nonetheless be continent. If this suburethral layer establishes its stability, albeit at a lower level, this mechanism could remain effective (Fig. 3).

\section{Coordination problems}

The essence of this urethral support concept is its multifaceted nature. There is no single structure that provides urethral support, but rather support is provided by the coordinated action of fasciae and muscles under neural control acting as an integrated unit. The pelvic muscles are known to contract during increases in abdominal pressure, indicating their potential participation in preventing urinary loss. Changes in pelvic nerve function have also been shown to be associated with stress incontinence, and this may influence continence by resulting in weaker muscles or through loss of muscle coordination. In addition, even if the muscle and its nerve supply is intact a patient might have a defect in the connection between the fascia supporting the urethra such that muscular contraction is mechanically uncoupled from urethral support. Damage to any element of the stress-continence control system might lessen a women's ability to remain continent during increases in abdominal pressure. Recent observations in our unit demonstrate that certain stress-incontinent women can significantly decrease incontinence in a single visit simply by learning to contract their pelvic muscles in anticipation of a cough [20]. In these women the muscles have not become stronger, nor have connective tissues healed. These individuals have simply recreated the normal coordination of pelvic muscle contraction that they presumably had lost. More research will be needed to
Fig. 3 A. Diagram showing abdominal pressure closing the urethra against the underlying urethral supports. B. In this diagram the supporting tissues are unstable and do not form a firm layer against which the urethra can be compressed. C. A cystourethrocele in which the urethra is much lower than normal but has a strong supportive layer that allows urethral compression [8]
A

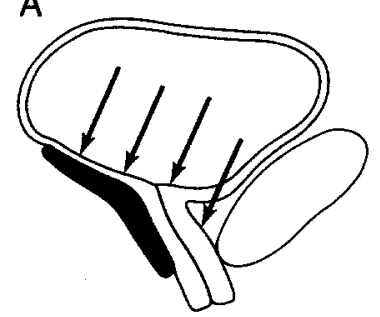

B

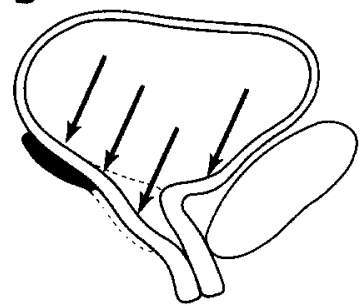

C

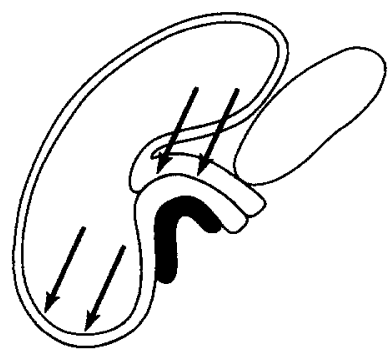


determine how many women with stress incontinence lack this normal precontraction of the pelvic muscles and which women can reprogram their pelvic muscles to achieve continence.

Sphincter problems: vesical neck and urethra

In addition to lower-urinary-tract support, vesical neck and urethral structure should also contribute to continence. The term vesical neck is a regional and functional one as previously discussed and does not refer to a single anatomic entity. It denotes that area at the base of the bladder where the urethral lumen passes through the thickened musculature of the bladder base. It has come to be considered separately from the bladder and urethra because there are some unique functional characteristics of this area. Specifically, loss of adrenergic stimulation or damage to this area results in its failure to close properly, and when this is the cause of stress incontinence, simple urethral suspension is often ineffective in curing this problem [18].

Some plausible hypothesis as to why poor vesical neck closure might influence continence is needed. Although difficult to prove, it seems likely that the change in bladder-base shape may be influential [14]. Increased fluid pressure in a container acts perpendicularly to the walls. When the bladder base is flat this pressure tends not to dilate the bladder. However, when funneling occurs, then an wedge-shaped bolus of urine exists that can drive the urethra open despite its normal support. That collagen injection, which changes the shape of the vesical neck lumen but not the closure pressure, alleviates stress incontinence is consistent with this hypothesis.

\section{Urethra}

Common practice has been to discount the urethra's role in maintaining continence because urethral suspension cures incontinence without changing the urethral closure pressure. The creation of an artificial continence mechanism, however, does not allow us to make conclusions about normal continence, and several observations support the concept that the urethra does play a role in continence. First, women with stress incontinence have lower urethral closure pressures $\left(34 \mathrm{cmH}_{2} \mathrm{O}\right)$ as compared with a group of age-matched continent women $\left(68 \mathrm{cmH}_{2} \mathrm{O}\right)$ [13]. Second, excision of the distal urethra can create stress incontinence in previously continent women [24]. Third, in $50 \%$ of continent women, urine passes the level of the vesical neck in response to coughing, only to be returned to the bladder by the urethral musculature [29]. Although women who are continent at the vesical neck do not need urethral function to remain dry, those in whom urine passes beyond this level do.

The urethra is a complex tubular viscus extending below the bladder. Embedded within its substance are a
Table 1 Topography of urethral and paraurethral structures ${ }^{a, b}$

Approximate Region of the urethra Paraurethral structures location

\begin{tabular}{lll}
\hline $0-20$ & Intramural urethra & $\begin{array}{l}\text { Urethral lumen traverses } \\
\text { the bladder wall } \\
\text { Sphincter urethrae muscle } \\
\text { Pubovesical muscle } \\
\text { Vaginolevator attachement } \\
\text { Compressor urethrae } \\
\text { muscle }\end{array}$ \\
G0-80 & Perineal membrane & $\begin{array}{l}\text { Urethrovaginal sphincter } \\
\text { muscle } \\
\text { Bulbocavemosus muscle }\end{array}$ \\
\hline
\end{tabular}

${ }^{a}$ Smooth muscle of the urethra was not considered

${ }^{\mathrm{b}}$ Expressed as percentage of the total urethral length

${ }^{c}$ Reprinted with permission from the American College of $\mathrm{Ob}$ stericians and Gynecologists [8]

number of elements that are important to lower-urinarytract dysfunction. Their locations are summarized in Table 1 [6]. Both the muscle of the striated urogenital sphincter muscle and the smooth muscle act to constrict the urethral lumen [26]. These structures not only diminish with age [5] but also show evidence of denervation injury [11].

\section{Innervation}

Recent studies have demonstrated alterations in pudendal nerve function in women with stress urinary incontinence $[27,28]$. At present it is unclear why this neuropathy results in decreased continence. The strength of the association between stress incontinence and neuropathy, however, suggests that it should be seriously considered. Nerve damage might change several things about the continence mechanism, resulting in decreased reserve. Loss or weakening of levator ani muscle contraction during a cough could destabilize the supportive layer and prevent abdominal pressure from being capable of compressing the urethra against the endopelvic fascia. In addition, decreases in urethral closure pressure would diminish the pressure differential that need be overcome to cause incontinence. Specific testing of these hypotheses will be needed to determine whether they are relevant and how frequently they occur as a cause of incontinence.

There are several levels at which the continence mechanism can fail. The endopelvic fascia may detach from its lateral attachments (paravaginal defect) and this may involve the levator ani muscles. The normal neural control of the muscle may be lost such that contraction cannot occur, or it may not be activated at the right time. The vesical neck may fail to close and the urethra may not have sufficient constriction that it can keep urine from escaping once the vesical neck has been transgressed. It is likely that most women have a combination of defects and that sorting them out will require large studies of incontinent and continent women. 


\section{Will it make any difference to understand the details of how the continence mechanism works?}

One wonders whether a better understanding of continence physiology could lead to improved treatment outcomes for incontinent women. Why would a change from empirically based treatment to therapy directed at an exact understanding of the defects involved in incontinence make a difference? The following story [9] is provided to call attention to the difference between empirically based treatments as currently used and those based on knowledge of the specific nature of an individual's injury.

Imagine that you have fallen, twisting your left leg awkwardly beneath you. As you get up you find that your leg is difficult to control and that the knee seems unstable. An orthopedic surgeon examines your leg in the emergency room, confirms that your knee moves abnormally, and diagnoses genu instabilicus. He suggests an operation to fuse your knee permanently in a straight position to eliminate the instability.

The problems with this approach are immediately apparent. First, an accurate anatomic diagnosis has not been made. Is the cartilage torn? Is collateral ligament ruptured? Did the quadriceps tendon avulse from the patella? Might you have injured a nerve that has altered muscular control? In consideration of these questions it is apparent that the physician's diagnosis has simply reiterated your symptoms in a medical-sounding phrase. It has not established what is wrong with the anatomic components of the knee. In addition, an operation has been planned that may solve the instability but will disrupt normal function. The surgeon may be quite satisfied that your knee does not wobble after the operation, but you may not be happy hobbling around on a stiff leg.

As obvious as the problems with this scenario are, the diagnostic and therapeutic approach it illustrates is uncomfortably close to the current diagnosis and treatment of stress urinary incontinence. A woman seeking care for incontinence who says she is wet when she coughs, sneezes, or performs activities that increase abdominal pressure is examined, tested, and told she has stress urinary incontinence. This gives a name to the symptoms she has provided. It does not, however, say anything about the actual damage that has occurred, be it neurologic, ligamentous, or muscular. Treatment is sometimes instituted irrespective of the specific anatomic lesion involved. If surgery is proposed, it may cure the incontinence but may lead to loss of other normal urinary tract function in the form of difficulty with normal urination [16], new detrusor instability [4], or pelvic organ prolapse in the form of an enterocele [30]. Alternatively, pelvic muscle exercise may be prescribed, which helps many (but by no means all) women, and is implemented regardless of whether a patient has intact innervation to her pelvic floor muscles or whether the muscles have become detached from their connections.
Pelvic-muscle exercise

One definite way in which an understanding of the specific continence-system injuries might improve our treatment concerns the effectiveness of pelvic muscle exercise. Women with stress urinary incontinence are often told to perform pelvic muscle exercise to improve their continence. An individual who has sustained significant denervation at the time of vaginal birth and who has lost all control of her pelvic muscles could not be expected to improve any more than paraplegics could be expected to improve their leg-muscle strength. Since half of women treated with muscle strengthening fail to reduce their wetting episodes by $50 \%$ and only about one in six is dry [3], the question as to why this treatment is variably effective arises.

A woman who has lost the nerve supply to the pelvic muscles will not succeed in improving continence with pelvic muscle exercise. Similarly, a women whose muscles have been torn from their normal attachments might not be expected to get better. On the other hand, dramatic improvements in continence occur in women who have lost the normal unconscious activation of the pelvic muscles during a cough but are capable of learning that skill. Women whose muscles contract normally but are too weak to maintain continence can exercise their muscles such that the latter become strong enough to withstand the forces placed on them.

Precision in patient selection might improve the success of pelvic muscle education without changing the regimens used. If we can exclude as inappropriate candidates for this mode of therapy all women who have lost the nerve supply to the muscles and those in whom urethral supports have become disconnected from the muscles, then the success of the pelvic-muscle skill instruction and pelvic muscle strengthening will rise.

Women destined from the start to fail muscle training because of their anatomic or functional abnormality should be triaged into other effective therapy and saved the frustration and expense of trying something they cannot do.

\section{Voiding paradox}

Another way in which an understanding of the dynamic nature of continence helps us to understand clinical problems concerns postoperative voiding difficulties seen in women whose urethras are sewn immovably to bone. There is an ironic paradox between the concept of normal continence control and the operations for stress incontinence. Many women void by increasing abdominal pressure to facilitate bladder emptying. Although this is not a normal mechanism, it is quite commonly used and is responsible for a voiding mechanism in approximately one-fourth of stress-incontinent women. This is accomplished through relaxation of the pelvic floor musculature, which puts the continence mechanism 
in a configuration in which increases in abdominal pressure favor emptying.

Operations do not change the resting urethral pressure. The goal of stress incontinence surgery is to create perfect pressure transmission, where increases in abdominal pressure are countered by equal or greater increases in urethral closure pressure. Therefore, if an operation achieves success by permanently fixing the urethra in place where pressure transmission is perfect, that women loses the ability to void or to augment urination by the Valsalva maneuver. In women who have previously voided by the Valsalva maneuver the detrusor muscle must be reawakened to contact before complete emptying can occur. If there is sufficient nerve loss to the detrusor muscle that it cannot be called into action, then spontaneous voiding cannot occur. In these individuals there are only two possibilities: some stress incontinence and the ability to empty the bladder by the Valsalva maneuver or no stress incontinence and the need for intermittent self-catheterization. This highlights the importance of the dynamic nature of the continence mechanism and its ability to switch between pressure transmission and voiding function. That this is under muscular control is supported by Bump et al.'s observations [2] that pressure transmission is decreased when the muscles of the pelvic floor are paralyzed.

\section{Is absolute continence a realistic goal?}

The assumption of the surgical literature that absolute stress continence under all circumstances is required for an operation to be judged effective is against normal continence physiology. Approximately $40 \%$ of healthy nulliparous women are incontinent during vigorous exercise [22]; therefore, attempts to create continence mechanism that is proof against these stresses means that we will have to improve upon the normal continence mechanism. Our only ability to do this would be to distort the continence mechanism abnormally such that it be permanently in a state of continence, which means that we would sacrifice voiding function at the same time.

\section{Concluding thoughts}

In his fourth book of laws, Hippocrates observed: "There are in fact two things, science and opinion; the first begets knowledge, the second ignorance". This is, perhaps, an overly harsh condemnation of opinion. From opinion and careful observations come important truths that are subsequently proved. On the other hand, it emphasizes that opinions differ and that science is required to distinguish the firmly held prejudice from the fundamental principle.

It has long been maintained that stress urinary incontinence is caused primarily by a loss of urethral support. It is curious that this idea is rarely challenged since some studies fail to reveal a difference between urethral support in stress-continent and stress-incontinent women [12]. There is a real and consistent difference in the average maximal urethral closure pressure measured in incontinent and continent women, yet the urethra has largely been ignored as part of the pathophysiology $[13,28]$. This remarkable resistance to the acceptance of scientific data likely comes from surgeons' desire to believe that they are recreating the normal. It is hard for us to accept that out operations for stress incontinence are empirical and bypass the normal continence mechanism. Recognition that operations create a new form of continence should not make us any less enthusiastic about their effectiveness. That a gastric exclusion operation corrects obesity does not suggest that an abnormally large stomach is responsible for obesity, nor does the failure of this surgery to address the cellular and behavioral problems involved in obesity make the operation any less effective. We must begin to accept the empirical nature of our operations and recognize both their advantages and their disadvantages. This will lead us to a proper recognition of the damage existing in individual women and toward the selection of treatment that is appropriate for the damage present.

\section{References}

1. Bonney V (1923) On diurnal incontinence of urine in women. J Obstet Gynaecol Br Emp 30: 358-365

2. Bump RC, Huang KC, McClish DK, et al. (1991) Effect of narcotic anesthesia and skeletal muscle paralysis on passive dynamic urethral function in continent and stress incontinent women. Neurourol Urodyn 10: 523-532

3. Burns PA, Pranikoff K, Nochajski TH, Hadley EC, Levy KJ, Ory MG (1993) A comparison of effectiveness of biofeedback and pelvic muscle exercise treatment of stress incontinence in older community-dwelling women. J Gerontol 48: M167-M174

4. Cardozo LD, Stanton SL, Williams JE (1979) Detrusor instability following surgery for genuine stress incontinence. $\mathrm{Br} \mathrm{J}$ Urol 51: 204-207

5. Carlile A, Davies I, Rigby A, Brocklehurst JC (1988) Age changes in the human female urethra: a morphometric study. J Urol 139: 532-535

6. DeLancey JOL (1986) Correlative study of paraurethrai anatomy. Obstet Gynecol 68: 91-97

7. DeLancey JOL (1988) Structural aspects of the extrinsic continence mechanism. Obstet Gynecol 72: 296-301

8. DeLancey JOL (1994) Structural support of the urethra as it relates to stress urinary incontinence: the hammock hypothesis. Am J Obstet Gynecol 170: 1713-1720

9. DeLancey JOL (1996) Stress urinary incontinence: where are we now, where should we go? Am J Obstet Gynecol 175: 311-319

10. DeLancey JOL, Starr RA (1990) Histology of the connection between the vagina and levator ani muscles. J Reprod Med 35: $765-771$

11. DeLancey JOL, Peschers UM, Schaer GN (1996) Discordant striated muscle/connective tissue ratio in different parts of the striated urogenital sphincter. Neurourol Urodyn 15: 153-154

12. Fantl JA, Hurt WG, Bump RC, Dunn LJ, Choi SC (1986) Urethral axis and sphincteric function. Am J Obstet Gynecol 155: $554-558$

13. Hilton P, Stanton SL (1983) Urethral pressure measurement by microtransducer: the results in symptom-free women and in those with genuine stress incontinence. Br J Obstet Gynaecol 90: $919-933$ 
14. Hutch JA (1967) A new theory of the anatomy of the internal urinary sphincter and the physiology of micturition. V. The base plate theory. Obstet Gynecol 30: 309-317

15. Kelly HA, Dumm WM (1914) Urinary incontinence in women, without manifest injury to the bladder: a report of cases. Surg Gynecol Obstet 18: 444-450

16. Lose $G$, Jorgensen L, Mortensen SO, Molsted-Pedersen L, Kristensen (1987) Voiding difficulties after colposuspension. Obstet Gynecol 69: 33-38

17. Marshall VF, Marchetti AA, Krantz KE (1949) The correction on stress incontinence by simple vesicourethral suspension. Surg Gynecol Obstet 88: 509-517

18. McGuire EJ (1987) Urodynamic findings in patients after failure of stress incontinence operations. Prog Clin Biol Res 78: 351-360

19. McGuire EJ, Lytton B, Pepe V, Kohorn EI (1976) Stress urinary incontinence. Obstet Gynecol 47: 255-264

20. Miller J, Ashton-Miller JA, DeLancey JOL (1996) The knack: use of precisely P-timed pelvic muscle contraction can reduce leakage in SUI. Neurourol Urodyn 15: 392-393

21. Muellner SR (1951) Physiology of micturition. J Urol 65: 805810

22. Nygaard I, DeLancey JOL, Arnsdorf L, Murphy EM (1990) Exercise and incontinence. Obstet Gynecol 75: 848-851
23. Parks AG, Porter NH, Melzak (1962) Experimental study of the reflex mechanism controlling muscles of the pelvic floor. Dis Colon Rectum 5: 407-414

24. Reid GC, DeLancey JOL, Hopkins MP, Roberts JA, Morley GW (1990) Urinary incontinence following radical vulvectomy. Obstet Gynecol 75: 852-858

25. Richardson AC, Lyons JB, Williams NL (1976) A new look at pelvic relaxation. Am J Obstet Gynecol 126: 568-573

26. Rud T, Anderson KE, Asmussen M, Hunting A, Ulmsten U (1980) Factors maintaining the intraurethral pressure in women. Invest Urol 17: 343-347

27. Smith ARB, Hosker GL, Warrell DW (1989) The role of pudendal nerve damage in the aetiology of genuine stress incontinence in women. Br J Obstet Gynaecol 96: 29-32

28. Snooks SJ, Badenoch DF, Tiptaft RC, Swash M (1985) Perineal nerve damage in genuine stress urinary incontinence. An electrophysiological study. Br J Urol 57: 422-426

29. Versi E, Cardozo LD, Studd JWW, Brincat M, O'Dowd TM, Cooper DJ (1986) Internal urinary sphincter in maintenance of female continence. BMJ 292: 166-167

30. Wiskind AK, Creighton SM, Stanton SL (1992) The incidence of genital prolapse after the Burch colposuspension. Am J Obstet Gynecol 167: 399-404 